\title{
Correlation of isocitrate lyase activity and riboflavin formation in the riboflavin overproducer Ashbya gossypii
}

\author{
Georg Schmidt, ${ }^{1}$ K.-Peter Stahmann, ${ }^{1}$ Bruno Kaesler ${ }^{2}$ \\ and Hermann Sahm ${ }^{1}$
}

Author for correspondence: K.-Peter Stahmann. Tel. +49 2461 612843. Fax: +49 2461612710.

1 Institut für Biotechnologie 1, Forschungszentrum Jülich GmbH, D-52425 Jülich, Germany

2 Forschung Feinchemikalien, Hauptlabor BASF AG 67056 Ludwigshafen, Germany

\begin{abstract}
Isocitrate lyase (ICL) was assayed during batch cultivations of Ashbya gossypii on soybean oil or glucose as carbon source. On soybean oil, a correlation between enzyme activity and riboflavin synthesis was observed. On glucose as carbon source, riboflavin overproduction started in the late growth phase when glucose was exhausted. ICL activity appeared in parallel and reached a maximum of $0.41 \mathrm{U}$ (mg protein) ${ }^{-1}$. This suggested synthesis of vitamin $\mathrm{B}_{2}$ from the intracellular reserve fat. ICL specific activity correlated with the enzyme concentration detected by specific antibodies. Itaconate, an efficient inhibitor of ICL, was used as an antimetabolite to screen mutants with enhanced ICL activity. Cultivations of an itaconate-resistant mutant on soybean oil revealed a $15 \%$ increase in enzyme specific activity and a 25 -fold increase in riboflavin yield compared to the wild-type. On the other hand, growth experiments on glucose resulted in an eightfold increase in riboflavin yield but showed a $33 \%$ reduction in ICL specific activity compared to the wild-type grown on the same medium. These results support the idea of an ICL bottleneck in the riboflavin overproducer A. gossypii when plant oil is used as the substrate.
\end{abstract}

Keywords: Ashbya gossypii, isocitrate lyase, riboflavin production, antimetabolite-resistant mutant

\section{INTRODUCTION}

Riboflavin, also called vitamin $B_{2}$, is a precursor of the coenzymes FMN and FAD. Dietary supplements with pure vitamin $B_{2}$ prevent deficiencies in the nutrition of humans and domestic animals (Cooperman \& Lopez, 1984). About 2000 tonnes per annum are produced worldwide both by chemical synthesis and by fermentation processes, with the latter gaining more significance in application (Vandamme, 1992). Other than some bacteria and yeasts, the best riboflavin overproducers are the ascomycetes Eremotbecium ashbyii and Asbbya gossypii (Yoneda, 1984). A. gossypii is preferred for production because of its higher genetic stability (Demain, 1972). Biosynthesis (Bacher, 1990), regulation and production parameters (Demain, 1972) have been studied thoroughly, resulting in well established fermentation processes with a reported maximum yield of $15 \mathrm{~g} \mathrm{l}^{-1}$ (Bigelis, 1989). Further yield improvement seems to be possible, since

Abbreviations: BCIP, 5-bromo-4-chloro-3-indolyl phosphate; ICL, isocitrate lyase; NBT, nitro blue tetrazolium chloride. supplementation with precursors of the riboflavin molecule, i.e. glycine (Hanson, 1967; Perlman, 1979) or ribitol (Mehta et al., 1972), as well as the use of plant oils in the fermentation process (Lago \& Kaplan, 1981, Özbas \& Kutsal, 1986), enhance production efficiencies, indicating a limitation in biosynthesis by primary metabolites. Therefore the elucidation of the fat metabolism of $A$. gossypii in connection with riboflavin synthesis has become a challenging objective.

The glyoxylate cycle is essential for using plant oil as the sole carbon source. Isocitrate lyase (ICL, tbreo- $\mathbf{D}_{\mathbf{s}^{-}}$ isocitrate glyoxylate-lyase, EC 4.1.3.1), the key enzyme of this anaplerotic pathway, directs the carbon flux into a carbon-conserving pathway and therefore has a determinative role with respect to growth and riboflavin synthesis. ICL from $A$. gossypii has recently been isolated and characterized (Schmidt et al., 1996).

In the present study, the investigation of a possible correlation between ICL activity and riboflavin formation was the primary goal. Furthermore, this correlation was to be demonstrated by the isolation and characterization of an ICL mutant of $A$. gossypii. 
Secondly, the regulation of ICL activity was an objective, since possible effectors with physiological significance for enzyme activity have not been identified and since ICL activity was not detectable during growth on glucose (Schmidt et al., 1996). Several models, in which enzyme synthesis and/or activity are regulated via the carbon source, have been introduced up to now. Catabolite repression, catabolite derepression and induction are regulation mechanisms concerning enzyme synthesis (Gancedo \& Gancedo, 1986; Gancedo, 1992). ICL activity is regulated by induction and repression in Aspergillus nidulans (Bowyer et al., 1994), Neurospora crassa (Gainey et al., 1991) and Phycomyces blakesleeanus (Rua et al., 1989). Covalent modification of enzyme protein resulting in a decreased enzyme specific activity is another regulation mechanism. This mode is classified as catabolite inactivation (Holzer, 1976), and was shown to work in Saccharomyces cerevisiae (Lopez-Boado et al., 1988) in addition to the repression and induction of ICL synthesis by glucose and ethanol, respectively (Gonzales, 1977). An immunological approach was taken to elucidate the kind of ICL regulation in $A$. gossypii because specific ICL antibodies were accessible with the purified enzyme.

\section{METHODS}

Organism and growth conditions. A. gossypii strain ATCC 10895 was obtained from BASF, Ludwigshafen, Germany. The fungus was maintained on solid medium (Stahmann et al., 1994). Inocula for batch cultures were grown in liquid medium consisting of $10 \mathrm{~g}$ yeast extract $\mathrm{l}^{-1}$ and $10 \mathrm{~g}$ soybean oil $\mathrm{l}^{-1}$ or $10 \mathrm{~g}$ glucose $1^{-1}$, respectively, and incubated at $28^{\circ} \mathrm{C}$ in $500 \mathrm{ml}$ shaking flasks, each containing $100 \mathrm{ml}$ medium, on a rotary shaker (Certomat H, B. Braun) at 120 r.p.m. For batch cultivations $2 \mathrm{ml}$ of these overnight cultures was used to inoculate $1000 \mathrm{ml}$ shaking flasks containing $300 \mathrm{ml}$ of the respective medium. They were incubated at $28^{\circ} \mathrm{C}$ on a rotary shaker (Pilot Shake, B. Braun) at 220 r.p.m. Samples were taken aseptically. Before autoclaving, the $\mathrm{pH}$ of all media was adjusted to 6.0 with $1 \mathrm{M} \mathrm{HCl}$.

Spore isolation and mutant screening. After 6-8 d growth on solid medium, mycelia were overlaid with a Novozym 234 (Novo Enzyme Products) solution $\left(10 \mathrm{mg} \mathrm{ml}^{-1}\right)$ and incubated for $1 \mathrm{~h}$ at room temperature with gentle shaking. The supernatant was decanted and centrifuged at $1500 \mathrm{~g}$ for $5 \mathrm{~min}$. The resulting pellet was resuspended in $\mathrm{H}_{2} \mathrm{O}$ and the same volume of paraffin was added. After vigorous shaking and subsequent phase separation the hydrophobic spores of $A$. gossypii were found in the upper paraffin layer while cell debris remained in the aqueous phase. The spore suspension could be stored for several months at $4{ }^{\circ} \mathrm{C}$ without losing the ability to germinate.

A Petri dish containing $40 \mathrm{ml}$ of a spore suspension $(50000$ spores $\left.\mathrm{ml}^{-1}\right)$ was exposed to UV light $(\lambda=260 \mathrm{~nm})$ for $30 \mathrm{~s}$ at a distance of $20 \mathrm{~cm}$ from an UV lamp (Schütt). The medium used for the screening of itaconate-resistant mutants consisted of $\left(1^{-1}\right)$ $10 \mathrm{~g}$ yeast extract, $0.05 \%(\mathrm{v} / \mathrm{v})$ oleic acid, $50 \mathrm{mM}$ itaconate and $20 \mathrm{~g}$ agar. It was prepared by emulsifying oleic acid with an Ultraturrax as long as the medium was still liquid. Spores were plated on that screening medium and incubated at $30^{\circ} \mathrm{C}$ for $3 \mathrm{~d}$.

Analytical methods. For the determination of mycelial dry weight, samples were taken from liquid cultures and filtered through MF membrane filters $(0 \cdot 8 \mu \mathrm{m}$ pore-size; Millipore).
Mycelia on the filters were freeze-dried in a Lyovac GT2 (Leybold) and weighed.

Residual glucose in the medium was determined enzymically with a hexokinase/glucose-6-phosphate dehydrogenase test kit obtained from Boehringer Mannheim.

For the determination of total riboflavin, samples taken from liquid cultures were disrupted in a French press (Aminco), then the resulting homogenate was filtered $(0.22 \mu \mathrm{m}$ pore-size; Millipore) and analysed for riboflavin by HPLC. Riboflavin was detected at $270 \mathrm{~nm}$ (Merck/Hitachi L-4200 UV-VIS detector) using an RP 18 125/4 column (Merck), which was developed isocratically with $50 \mathrm{mM} \mathrm{NaH} \mathrm{PO}_{4} / \mathrm{H}_{3} \mathrm{PO}_{4}$ buffer, $\mathrm{pH} 3 \cdot 0$, containing $1 \mathrm{mM}$ tetramethylammonium chloride and $12 \%(\mathrm{v} / \mathrm{v})$ acetonitrile at a flow rate of $1 \mathrm{ml} \mathrm{min}^{-1}$.

Protein concentrations were determined spectrophotometrically by the method of Bradford (1976) with the Serva Blue G dye binding reagent. BSA was used as a standard.

For crude extract preparation, mycelia were harvested by filtration (MF membrane filter, $0.8 \mu \mathrm{m}$ pore-size; Millipore), rinsed with distilled water and resuspended in homogenization

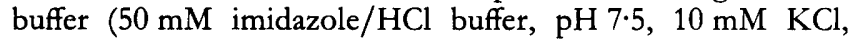
$1 \mathrm{mM}$ EDTA, $5 \mathrm{mM} \mathrm{MgSO}$, $5 \mathrm{mM}$ DTT, 30\%, v/v, glycerol, $1 \mathrm{mM}$ PMSF). Cells were disrupted in a French Press (Aminco) under 19000 p.s.i. $(131000 \mathrm{kPa})$, and the homogenate was centrifuged at $18000 \mathrm{~g}$ for $15 \mathrm{~min}$. The supernatant (crude extract) was separated from the pellet using a Pasteur pipette. Chilled instruments and solutions were used throughout.

ICL activity was assayed as described previously by Schmidt $e t$ al. (1996).

Discontinuous SDS-PAGE was run according to the method of Laemmli (1970) in a vertical slab gel instrument (Hoefer SE 400, Serva) using an $8 \%(\mathrm{w} / \mathrm{v})$ polyacrylamide gel. Electrophoresis was performed overnight at $8 \mathrm{~mA}$ constant current and monitored by application of prestained SDS $M_{\mathrm{r}}$ standards (Sigma).

Production of antibodies by injecting a rabbit with homogeneously prepared ICL protein (Schmidt et al., 1996) and preparation of the antiserum were performed according to the methods described by Cooper (1981).

Immunoblotting was performed to correlate the amount of ICL protein with activity of the enzyme. After SDS-PAGE, the slab gels were equilibrated in blot-buffer $(0.01 \mathrm{M}$ CAPS/ $\mathrm{NaOH}$, $\mathrm{pH} 11 \cdot 0$, containing $10 \%, \mathrm{v} / \mathrm{v}, \mathrm{MeOH}$; see User Bulletin no. 36, Applied Biosystems) for $30 \mathrm{~min}$, and proteins were transferred to an Immobilon-P transfer membrane (Millipore) using a Multiphor II NovaBlot electrophoretic transfer unit (Pharmacia). A constant current of $0.8 \mathrm{~mA} \mathrm{~cm}^{-2}$ was applied for $90 \mathrm{~min}$ (see Multiphor II Electrophoresis System, User's Manual, Pharmacia). The membrane was incubated for $1 \mathrm{~h}$ in

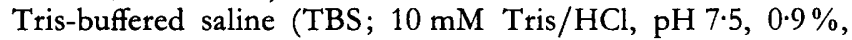
$\mathrm{w} / \mathrm{v}, \mathrm{NaCl}$ ) containing $3 \%(\mathrm{w} / \mathrm{v}) \mathrm{BSA}$. The TBS-BSA was removed and the membrane was further incubated for $1 \mathrm{~h}$ with ICL specific antiserum (dilution $1: 2000$ ) in wash buffer (TBS containing $0.3 \%, w / v, B S A$ and $0.1 \%, w / v$, Tween 20 ). After this incubation step the membrane was rinsed twice and washed for another two $15 \mathrm{~min}$ periods in wash buffer. Subsequently the membrane was incubated for $1 \mathrm{~h}$ with an anti-rabbit-antibody alkaline-phosphatase conjugate from sheep (Boehringer Mannheim; dilution 1:5000) in wash buffer followed by the same washing procedure as described before. All incubation and washing steps were carried out at $37^{\circ} \mathrm{C}$ with gentle shaking. Finally, the immunoblot was developed at room temperature 

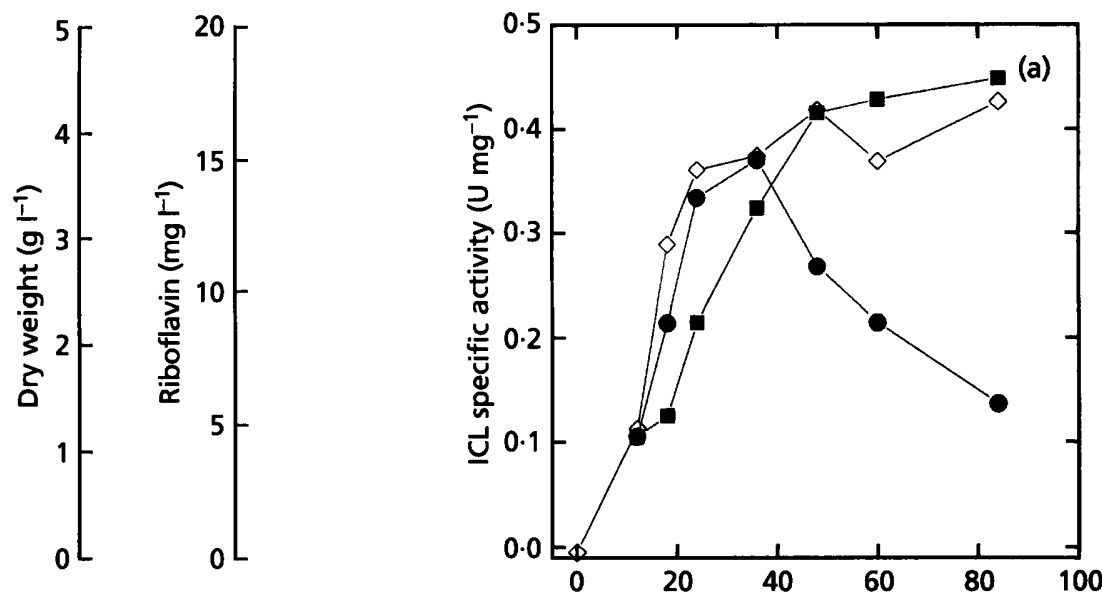

$\left.\right|_{0} ^{5}$
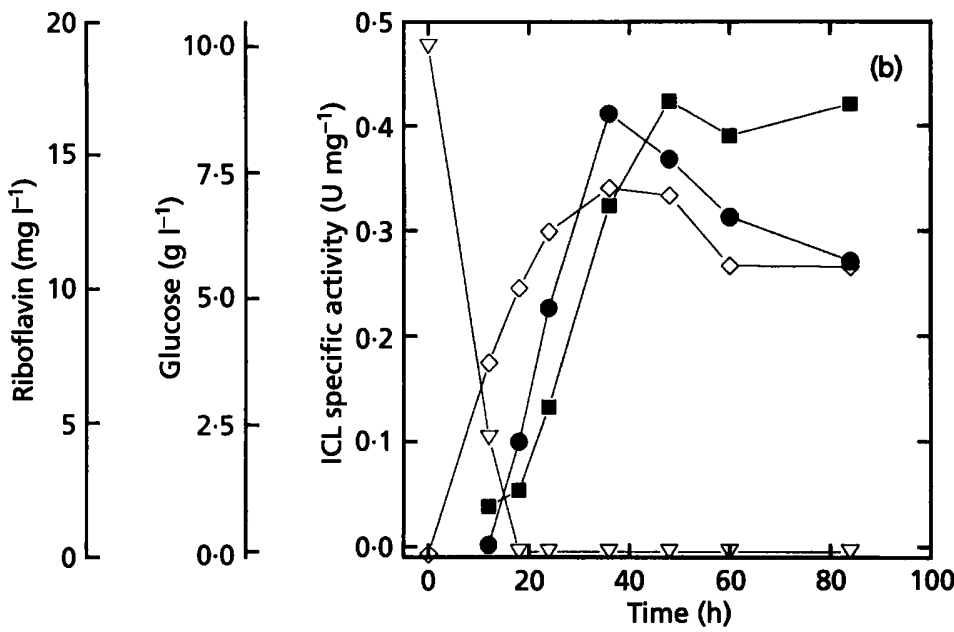

Fig. 1. Growth of $A$. gossypii wild-type on yeast extract with soybean oil (a) and glucose (b) as carbon source. The changes in dry weight $(\diamond)$, residual glucose $(\nabla)$, total riboflavin (D) and ICL specific activity (O) with time are shown. with the nitro blue tetrazolium chloride/5-bromo-4-chloro-3indolyl phosphate (NBT/BCIP) detection system (Boehringer Mannheim) according to the method described by Harlowe \& Lane (1988). The reaction was stopped by washing the membrane several times with distilled water.

\section{RESULTS}

\section{Correlation of riboflavin formation and ICL specific activity}

In order to study the time-course of riboflavin formation in relation to ICL specific activity, $A$. gossypii wild-type was cultured over a period of $82 \mathrm{~h}$. The growth curve on soybean oil as the substrate is shown in Fig. 1(a). ICL activity was rather low $\left.[0 \cdot 11 \mathrm{U} \text { (mg protein })^{-1}\right]$ at the beginning of soybean oil cultivation, but enzyme specific activity rose to a maximum value of $0.36 \mathrm{U}(\mathrm{mg} \text { protein })^{-1}$ and total riboflavin accumulated during growth. The pronounced decrease of enzyme activity after $36 \mathrm{~h}$ of cultivation was accompanied by a decline of growth and a subsequent decrease of riboflavin accumulation. The same growth experiment was performed using glucose as carbon source, because ICL activity was not detectable during growth on glucose (Schmidt et al., 1996) but riboflavin was produced. When glucose was exhausted from the medium, ICL activity appeared and increased to a maximum specific activity of $0.41 \mathrm{U}$ ( $\mathrm{mg}$ protein $)^{-1}$, accompanied by the start of production and subsequent accumulation of riboflavin (Fig. 1b). This unexpected result could be explained by a switch of metabolism to reserve fat degradation, which was shown recently by a decrease of neutral lipid in the mycelium and a respiration quotient of $0.6-0.7$ (Stahmann et al., 1994). The lag of riboflavin formation and ICL activity behind growth as well as their parallel increase after glucose exhaustion raised the question whether ICL activity could be a limiting factor in riboflavin synthesis. In order to examine this hypothesis, the effect of itaconate was tested.

\section{Effect of itaconate and screening for resistant mutants}

Itaconate was described as inhibiting the ICLs of $P$. blakesleeanus $\left(K_{\mathrm{i}}: 5.9 \mu \mathrm{M}\right.$; Rua et al., 1990) and Yarrowia lipolytica (Hönes et al., 1991) and particularly the purified ICL of $A$. gossypii $\left(K_{\mathrm{i}}: 170 \mu \mathrm{M}\right.$; Schmidt et al., 1996) very efficiently. Furthermore, it was reported to be a specific ICL inhibitor which is not metabolized (McFadden \& 
Purohit, 1977; Khan \& McFadden, 1979). For an application in a screening system for ICL mutants, its effect on growth and riboflavin synthesis was investigated on agar plates. Growth on a mineral salt medium containing $\left(\mathrm{l}^{-1}\right) 2 \mathrm{~g} \mathrm{KH}_{2} \mathrm{PO}_{4}$ (pH 6.7, adjusted with $6 \mathrm{M}$ $\mathrm{KOH}), 1.5 \mathrm{~g} \mathrm{NH}_{4} \mathrm{Cl}, 0.5 \mathrm{~g}$ asparagine, $0.2 \mathrm{~g} \mathrm{NaCl}, 0.4 \mathrm{~g}$ $\mathrm{MgSO}_{4} .7 \mathrm{H}_{2} \mathrm{O}, 0.05 \mathrm{~g} \mathrm{MnSO}_{4} . \mathrm{H}_{2} \mathrm{O}, 0.04 \mathrm{~g} \mathrm{CaCl}_{2} .2 \mathrm{H}_{2} \mathrm{O}$, $0.1 \mathrm{~g}$ inositol, $0.25 \mathrm{~g}$ niacinamide and $0.025 \%(\mathrm{v} / \mathrm{v})$ oleic acid as carbon source was inhibited by $20 \mathrm{mM}$ itaconate. Growth was not affected on that medium when glucose was used as carbon source. This result indicated an inhibition of an enzyme essential for growth on fatty acids, such as ICL. To check the effect on riboflavin synthesis, $A$. gossypii was cultured on agar plates containing $10 \mathrm{~g}$ yeast extract $\mathrm{l}^{-1}$ and $0.05 \%$ (v/v) oleic acid. Colonies showed a bright yellowing caused by riboflavin on this medium. Addition of $50 \mathrm{mM}$ itaconate inhibited colony yellowing completely. Thus, two systems concerning both growth inhibition and riboflavin overproduction were available to screen mutants overcoming the barrier set by itaconate.

Isolated ascospores of $A$. gossypii were treated with UV light for mutagenesis. A complete mortality of spores was reached by exposure of a suspension to UV radiation for $90 \mathrm{~s}$. In order to obtain mutants, a spore suspension was irradiated for $30 \mathrm{~s}(87 \%$ mortality) and 5000 spores were applied per agar plate. Spores did not germinate on the first screening system based on the mineral salt medium. Therefore spores were plated on the second screening system using the effect of inhibited riboflavin synthesis. One stable mutant (Ita-GS01) resistant to $50 \mathrm{mM}$ itaconate and showing colony yellowing was selected from 5000 colonies.

To check whether the Ita-GS01 strain produces more riboflavin due to an enhanced ICL activity, cultivations on soybean oil (Fig. 2a) and glucose (Fig. 2b) were carried out. ICL specific activity and the total amount of riboflavin were determined and compared to the wildtype, which was studied as a control in parallel. In general, mutant and wild-type revealed the same time-course of enzyme activity and riboflavin formation. However, the mutant was able to synthesize 25 -fold more riboflavin on soybean oil and 8-fold more riboflavin on glucose compared to the wild-type. The Ita-GS01 strain showed a significantly enhanced ICL activity on soybean oil (115\%) while exhibiting a significantly lower ICL specific activity on glucose $(67 \%)$ during riboflavin production. A potential diversity in kinetic properties of the mutant ICL enzyme responsible for the differences in ICL specific activity between mutant and wild-type could be ruled out, since crude extracts of the Ita-GS01 strain revealed no differences in the $K_{\mathrm{m}}$ value for isocitrate and the $K_{\mathrm{i}}$ value for itaconate compared to the data for the $A$. gossypii wildtype (Schmidt et al., 1996). Another striking feature shown by the mutant was the gap between ICL activity and riboflavin accumulation. On both carbon sources the mutant clearly formed riboflavin, although the ICL specific activity was decreasing. This gap was not observed in such a pronounced way for the $A$. gossypii wild-type (see Fig. 1a, b).
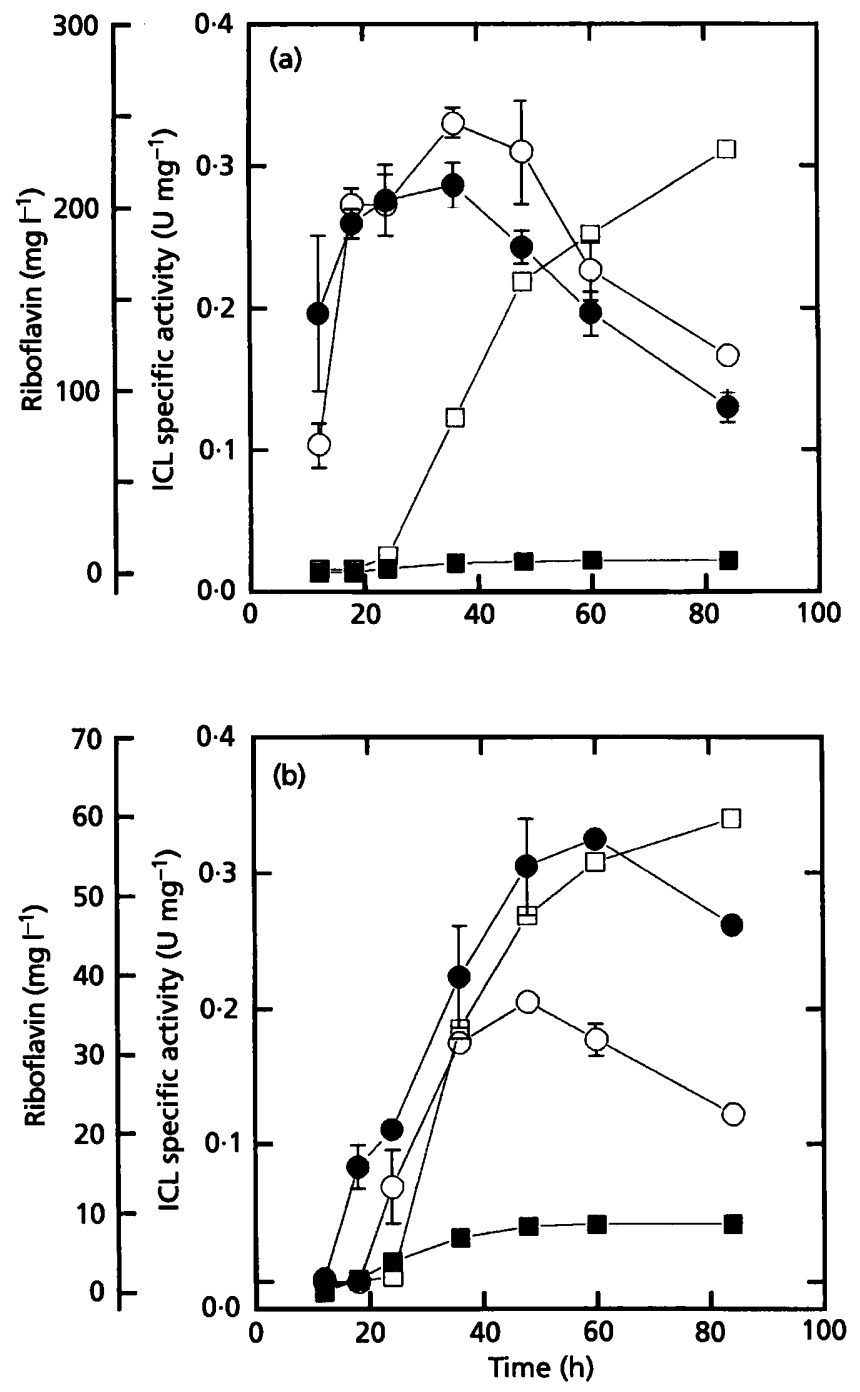

Fig. 2. Time-course of total riboflavin accumulation $(\square, \square)$ and ICL specific activity $(O, O)$ of $A$. gossypii wild-type (closed symbols) and itaconate-resistant mutant (open symbols) grown on yeast extract with soybean oil (a) and glucose (b) as carbon source. Data points for ICL specific activity represent mean values with standard deviations of triplicate fermentations on soybean oil (a) and of duplicate fermentations on glucose (b). For riboflavin only the respective mean values are given.

\section{ICL regulation in A. gossypii}

The significant differences in ICL specific activities between the wild-type and mutant indicated a change in ICL regulation. Two closely linked questions arose from that observation. It had to be discovered, firstly, whether an increased amount of ICL protein was responsible for the itaconate resistance of the mutant. Secondly, the level of regulation, most evident from the lack of enzyme activity during growth on glucose, had to be investigated. Therefore samples from a glucose fermentation of $A$. gossypii wild-type were collected to prepare crude extracts. After determination of enzyme specific activities, an analysis for ICL protein by the immunoblot technique was performed using specific ICL antisera. The specific 
(a)

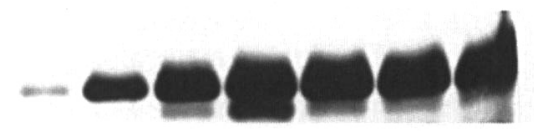

(b)

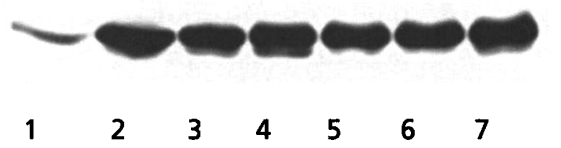

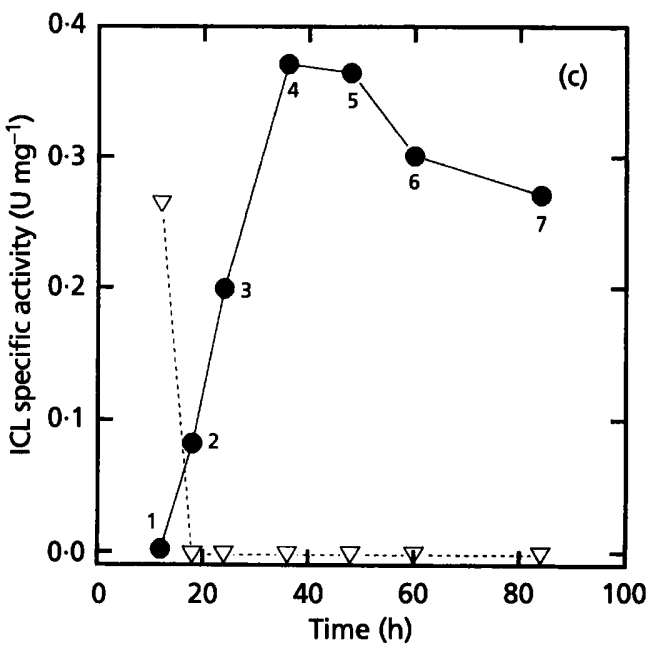

Fig. 3. Detection of ICL protein in samples of $A$. gossypii wildtype grown on glucose as carbon source using the immunoblot technique $(a, b)$. Crude extracts were prepared from aliquots taken at the indicated times, and specific ICL activity (O) was determined (c); $\nabla$, glucose concentration. Protein $(20 \mu \mathrm{g})$ from each extract was applied to an SDS-PAGE gel and transferred to an Immobilon-P membrane (a). In another SDS-PAGE gel, every lane was loaded with the amount of crude extract containing the same absolute enzyme activities, except for lane 1, to which $100 \mu \mathrm{g}$ protein was applied (b). Lanes 1-7 represent the respective data points of ICL activity shown in the graph.

ICL-antibody reaction was checked by carrying out immunoblotting with the control sera obtained prior to the first injection of the antigen. Under these conditions no blot signal was found. By applying the same amount of protein $(20 \mu \mathrm{g})$ to each lane of the SDS-PAGE gel, a correlation between ICL specific activity and immunoblot signal was observed, i.e. with increasing ICL specific activity an enlarged and more intensively coloured blot signal was visible (Fig. 3a). This correlation was also shown by applying the same absolute enzyme activities to each lane (Fig. $3 \mathrm{~b}$ ). In consequence, the immunoblot signals became amplified, except for that in lane 1 , in which even with $100 \mu \mathrm{g}$ protein no amplification could be achieved. The same immunoblot studies were performed with samples from soybean oil cultivations of the wildtype and with samples from the mutant, confirming the observed relationship between ICL activity and immunoblot signal. These results allowed the conclusion that ICL activity appeared as a result of de novo synthesis of the
Control

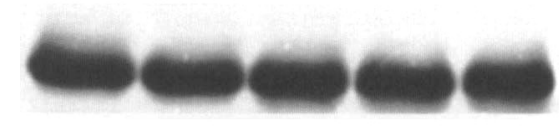

Pulsed culture
Time after pulse (h)...
0 0.5

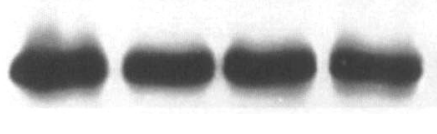

3 5

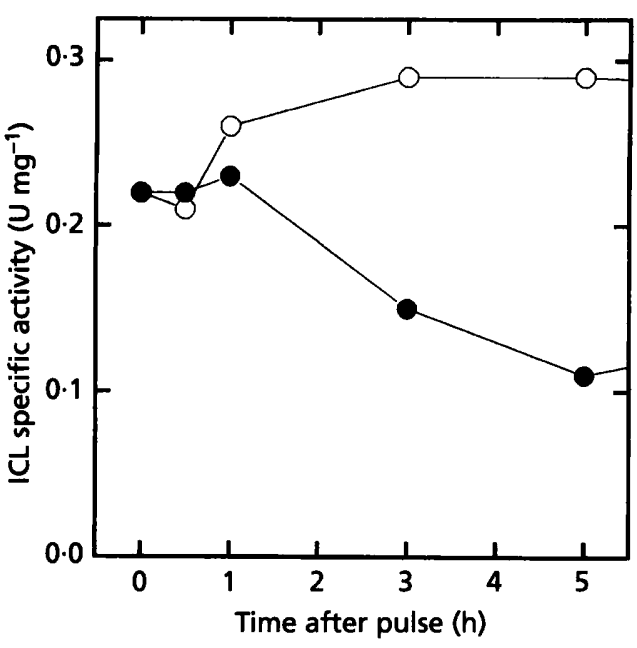

Fig. 4. Inactivation of $A$. gossypii ICL in vivo. Mycelium grown for $18 \mathrm{~h}$ on soybean oil was pulsed with $1 \%$ glucose (O) resulting in a final concentration of $10 \mathrm{~g} \mathrm{l}^{-1}$. Controls $(O)$ were left untreated. Crude extracts were prepared from aliquots taken at the indicated times, and specific ICL activity was determined (see graph). Protein $(20 \mu \mathrm{g})$ from each extract was applied per lane to the SDS-PAGE gel, transferred to an Immobilon-P membrane and stained using the NBT/BCIP reaction. Blots $0-5$ represent the respective data points of $I C L$ activity shown in the graph.

protein. When protein amounts representing equal enzyme activities from the wild-type and the Ita-GS01 strain were compared on the same blot, signals of equal intensity were also obtained, indicating an enhanced ICL protein synthesis of the mutant on soybean oil.

In order to examine a switch-off in ICL activity by glucose, an exponentially growing soybean oil culture of $A$. gossypii wild-type was pulsed with glucose giving a final concentration of $10 \mathrm{~g} \mathrm{l}^{-1}$. Samples from that culture were collected immediately before the addition of glucose and $0 \cdot 5,1,3$ and $5 \mathrm{~h}$ after setting the pulse. Samples from an untreated control were taken at the respective times. After preparation of crude extracts and determination of ICL specific activities an immunoblot analysis for ICL protein was performed (Fig. 4). A considerable loss of antigenic protein was detected in the samples taken $3 \mathrm{~h}$ and $5 \mathrm{~h}$ after setting the glucose pulse. The corresponding ICL specific activity of the pulsed culture had decreased at that time to approximately $50 \%$ and $30 \%$ of the respective control values. The kinetics of ICL inactivation indicated 
a slow mechanism again on the level of enzyme quantity. A simple dilution of enzyme protein due to repression of ICL synthesis and additional biomass production could not be responsible for the decrease in ICL specific activity, since the difference in dry weight between the pulsed culture and the control was determined to be only $15 \%$ after $5 \mathrm{~h}$.

\section{DISCUSSION}

The results of this study showed a simultaneous formation of riboflavin and ICL in $A$. gossypii. This was unexpected when glucose served as the carbon source. The timecourse of glucose consumption and riboflavin synthesis resembled the data obtained for large-scale fermentations of $A$. gossypii (Pfeifer et al., 1950), i.e. riboflavin synthesis started after glucose had been exhausted from the medium. Goodwin (1959) described experiments with up to $30 \mathrm{~g}$ glucose $\mathrm{l}^{-1}$ causing delays of detectable riboflavin formation for more than $30 \mathrm{~h}$. Interestingly, riboflavin accumulation started with the appearance of ICL. Therefore, riboflavin synthesis might be run from storage lipids depending on ICL activity. Growth experiments with soybean oil as carbon source confirmed the relationship between ICL activity and riboflavin synthesis, because riboflavin synthesis started with the increase of ICL specific activity.

The significance of ICL for riboflavin overproduction was emphasized by its itaconate sensitivity. The inhibition of riboflavin synthesis by itaconate supported the idea that ICL activity is a limiting factor in the carbon flux from plant oil as a substrate to the product riboflavin. Consistently, an itaconate-resistant mutant grown on soybean oil revealed a significantly increased ICL specific activity accompanied by a large overproduction of riboflavin compared to the wild-type. Furthermore, this effect gave evidence for a mutation in the regulation of ICL, although a mutation in a superior regulation system controlling ICL and other enzymes of riboflavin synthesis cannot be ruled out. An argument against the observed correlation of ICL activity and riboflavin formation was given by the gap in the time-course of ICL activity and riboflavin accumulation at the end of mutant cultivations. The same phenomenon, maximum riboflavin production lagging behind enzyme activities necessary for riboflavin precursor synthesis, was observed for ribitol kinase, ribose $5^{\prime}$-phosphatase and GMP nucleosidase in E. ashbyii, and it was explained by an involvement of these enzymes in making early precursor pools required for flavinogenesis (Mehta et al., 1972). This might also be the role of ICL in the riboflavin synthesis of $A$. gossypii. However, as no growth processes have to be sustained in the last phase of production, the residual ICL activity should be sufficient to run riboflavin synthesis.

As no physiological effectors for ICL activity (Schmidt $e t$ al., 1996) and no differences in the kinetic data of mutant and wild-type ICL were found, the type of enzyme regulation remained to be elucidated. A regulation of ICL activity through the amount of ICL protein triggered by the availability of glucose was shown for $A$. gossypii. A repressing effect of glucose on ICL activity, which was observed in this study, was also shown for $N$. crassa (Sjogren \& Romano, 1967), P. blakesleeanus (Rua et al., 1989), for different Candida species (Nabeshima et al., 1977; Okada et al., 1987) and for Y. lipolytica (Barth, 1985). In S. cerevisiae the highest ICL activities on ethanol, acetate and oleic acid required subrepressing amounts of glucose $(0.2 \%)$, but nevertheless, with higher glucose concentrations ICL gene expression was repressed (Schöler \& Schüller, 1993).

The amount of ICL protein in $A$. gossypii was additionally regulated by protein degradation as was shown by a glucose pulse experiment. Holzer (1976) introduced the term 'catabolite inactivation' for the phenomenon of glucose-induced inactivation of enzymes. In S. cerevisiae a two-step mechanism is involved in that catabolite inactivation process. The first step is related to the reversible inactivation by phosphorylation of the enzyme; in a second step, the loss of ICL activity is paralleled by a loss of ICL protein, suggesting a proteolytic mechanism (Lopez-Boado et al., 1987, 1988). Acetate-grown cultures of $P$. blakesleeanus transferred to glucose showed a reversible and irreversible phase of enzyme inactivation, also suggesting a phosphorylation prior to degradation of ICL protein (Rua et al., 1989). Although it was not explicitly shown by tracer experiments, a phosphorylation of the ICL of $A$. gossypii can be ruled out, because no significant decrease in specific ICL activity was observed during the first hour after setting the glucose pulse. An inactivation of an enzyme by phosphorylation should work within minutes after the pulse, as was demonstrated for the inactivation of fructose-1,6-bisphosphatase in yeast (Müller \& Holzer, 1981; Mazon et al., 1982). Therefore, the decreased ICL activity in $A$. gossypii was a consequence of protein degradation representing the irreversible step of catabolite inactivation only, which resembled the situation reported recently for $A$. nidulans (De Lucas et al., 1994).

Activation of ICL by phosphorylation was reported for the prokaryotic organisms Escherichia coli (Robertson et al., 1988; Hoyt et al., 1994) and Acinetobacter calcoaceticus (Hoyt et al., 1994) in spite of an ICL inactivation by phosphorylation in S. cerevisiae. In general, regulation of ICL activity by phosphorylation/dephosphorylation seems to be necessary in organisms where the enzyme is not sequestered in microbodies (Vanni et al., 1990), as $S$. cerevisiae ICL could not be localized in microbodies (McCammon et al., 1990).

In conclusion, compartmentation of ICL in A. gossypii will be the subject of future investigations. Ultimately, detailed information about the role of ICL in riboflavin synthesis should be obtained by the characterization of an ICL-knockout and an ICL-overexpressing mutant.

\section{ACKNOWLEDGEMENTS}

This work was supported by a grant from BASF, Ludwigshafen. We are very grateful to $R$. Kurth for helpful discussion and critical reading of the manuscript. Many thanks go to C.-L. Schimz and G. Decker for their help in the production of the 
antibodies used. We thank S. Peters and M. Romes for preparing the photographs and J. Carter-Sigglow for her linguistic advice.

\section{REFERENCES}

Bacher, A. (1990). Biosynthesis of flavins. In Chemistry and Biochemistry of Flavoenzymes, vol. 1, pp. 215-249. Edited by F. Müller. Boca Raton: CRC Press.

Barth, G. (1985). Genetic regulation of isocitrate lyase in the yeast Yarrowia lipolytica. Curr Genet 10, 119-124.

Bigelis, R. (1989). Industrial products of biotechnology : application of gene technology. In Biotechnology, vol. 7b, p. 243. Edited by H. J. Rehm \& G. Reed. Weinheim: VCH.

Bowyer, P., De Lucas, J. R. \& Turner, G. (1994). Regulation of the expression of isocitrate lyase gene (acuD) of Aspergillus nidulans. Mol E Gen Genet 242, 484-489.

Bradford, M. M. (1976). A rapid and sensitive method for the quantitation of microgram quantities of protein utilizing the principle of protein-dye binding. Anal Biochem 72, 248-254.

Cooper, T. G. (1981). The Tools of Biochemistry. Edited by R. Neumeier \& H. R. Maurer. Berlin: Walter de Gruyter.

Cooperman, J. M. \& Lopez, R. (1984). Riboflavin. In Handbook of Vitamins, pp. 299-327. Edited by L. J. Machlin. New York : Marcel Dekker.

De Lucas, J. R., Valenciano, S., Laborda, F. \& Turner, G. (1994). Glucose-induced inactivation of isocitrate lyase in Aspergillus nidulans. Arch Microbiol 162, 409-413.

Demain, A. L. (1972). Riboflavin oversynthesis. Annu Rev Microbiol 26, 369-388.

Gainey, L. D. S., Kölble, K. \& Connerton, I. F. (1991). Isolation and expression of the acetate-inducible isocitrate lyase gene $(a c u-3)$ from Neurospora crassa: evidence for a second constitutive enzyme. Mol $\mathcal{E}$ Gen Genet 229, 253-260.

Gancedo, J. M. (1992). Carbon catabolite repression in yeast. Eur J Biochem 206, 297-313.

Gancedo, J. M. \& Gancedo, C. (1986). Catabolite repression mutants of yeast. FEMS Microbiol Rev 32, 179-187.

Gonzales, E. (1977). Two-carbon assimilative capacity and the induction of isocitrate lyase in Saccharomyces cerevisiae. J Bacteriol 129, 1343-1348.

Goodwin, T. W. (1959). Production and biosynthesis of riboflavin in micro-organisms. In Progress in Industrial Microbiology, vol. 1, pp. 139-177. Edited by D. J. D. Hockenhull. London: Heywood \& Company.

Hanson, A. M. (1967). Microbial production of pigments and vitamins. In Microbial Technology, pp. 222-250. Edited by H. J. Peppler. New York: Reinhold.

Harlowe, E. \& Lane, D. (1988). Antibodies: a Laboratory Manual. Cold Spring Harbor: Cold Spring Harbor Laboratory.

Holzer, H. (1976). Catabolite inactivation in yeast. Trends Biochem Sci $1,178-181$.

Hones, I., Simon, M. \& Weber, H. (1991). Characterization of isocitrate lyase from the yeast Yarrowia lipolytica. J Basic Microbiol 31, 251-258.

Hoyt, J. C., Lin, H.-P. P. \& Reeves, H. C. (1994). In vivo phosphorylation of isocitrate lyase in Escherichia coli and Acinetobacter calcoaceticus. Curr Microbiol 28, 67-69.

Khan, F. R. \& McFadden, B. A. (1979). Enzyme profiles in seedling development and the effect of itaconate, an isocitrate lyase-directed reagent. Plant Pbysiol 64, 228-231.
Laemmli, U. K. (1970). Cleavage of structural proteins during the assembly of the head of bacteriophage T4. Nature 227, 680-685.

Lago, B. D. \& Kaplan, L. (1981). Vitamin fermentations: $\mathrm{B}_{2}$ and $\mathrm{B}_{12}$. Adv Biotechnol 3, 241-246.

Lopez-Boado, Y. S., Herrero, P., Gascon, S. \& Moreno, F. (1987). Catabolite inactivation of isocitrate lyase from Saccharomyces cerevisiae. Arch Microbiol 147, 231-234.

Lopez-Boado, Y. S., Herrero, P., Fernandez, T., Fernandez, R. \& Moreno, F. (1988). Glucose-stimulated phosphorylation of yeast isocitrate lyase in vivo. J Gen Microbiol 134, 2499-2505.

Mazon, M. J., Gancedo, J. M. \& Gancedo, C. (1982). Inactivation of yeast fructose-1,6-bisphosphatase. J Biol Chem 257, 1128-1130.

McCammon, M. T., Veenhuis, M., Trapp, S. B. \& Goodman, J. M. (1990). Association of glyoxylate and beta-oxidation enzymes with peroxisomes of Saccharomyces cerevisiae. J Bacteriol 172, 5816-5827.

McFadden, B. A. \& Purohit, S. (1977). Itaconate, an isocitrate lyasedirected inhibitor in Pseudomonas indigofera. J Bacteriol 131, 136-144.

Mehta, S. M., Mattoo, A. K. \& Modi, V. V. (1972). Ribitol and flavinogenesis in Eremothecium ashbyii. Biochem J 130, 159-166.

Muller, D. \& Holzer, H. (1981). Regulation of fructose-1,6bisphosphatase in yeast by phosphorylation/dephosphorylation. Biochem Biophys Res Commun 103, 926-933.

Nabeshima, S., Tanaka, A. \& Fukui, S. (1977). Effect of carbon sources on the level of glyoxylate cycle enzymes in n-alkaneutilizable yeasts. Agric Biol Chem 41, 275-279.

Okada, H., Ueda, M., Uchida, M. \& Tanaka, A. (1987). Isocitrate lyase and malate synthase of Candida tropicalis grown on different carbon sources. Agric Biol Chem 51, 869-875.

Özbas, T. \& Kutsal, T. (1986). Comparative study of riboflavin production from two microorganisms: Eremotbecium asbbyii and Asbbya gossypii. Enzyme Microb Technol 8, 593-596.

Perlman, D. (1979). Microbial process for riboflavin production. In Microbial Tecbnology, Microbial Processes, 2nd edn, vol. 1, pp. 521-527. Edited by H. J. Peppler \& D. Perlman. New York: Academic Press.

Pfeifer, V. F., Tanner, F. W., Jr, Vojnovich, C. \& Traufler, D. H. (1950). Riboflavin by fermentation with Asbbya gossypii. Ind Eng Chem 42, 1776-1781.

Robertson, E. F., Hoyt, J. C. \& Reeves, H. C. (1988). Evidence of histidine phosphorylation in isocitrate lyase from Escherichia coli. $J$ Biol Chem 263, 2477-2482.

Rua, J., De Arriaga, D., Busto, F. \& Soler, J. (1989). Effect of glucose on isocitrate lyase in Pbycomyces blakesleeanus. J Bacteriol 171, 6391-6393.

Rua, J., De Arriaga, D., Busto, F. \& Soler, J. (1990). Isocitrate lyase from Pbycomyces blakesleeanus. Biochem J 272, 359-367.

Schmidt, G., Stahmann, K.-P. \& Sahm, H. (1996). Inhibition of purified isocitrate lyase identified itaconate and oxalate as potential antimetabolites for the riboflavin overproducer Asbbya gossypii. Microbiology 142, 411-417.

Schöler, A. \& Schuller, H.-J. (1993). Structure and regulation of the isocitrate lyase gene ICL1 from the yeast Saccharomyces cerevisiae. Curr Genet 23, 375-381.

Sjogren, R. E. \& Romano, A. H. (1967). Evidence for multiple forms of isocitrate lyase in Neurospora crassa. J Bacteriol 93, 1638-1643.

Stahmann, K.-P., Kupp, C., Feldmann, S. D. \& Sahm, H. (1994). Formation and degradation of lipid bodies found in the riboflavinproducing fungus Asbbya gossypii. Appl Microbiol Biotechnol 42, 121-127. 
Vandamme, E. J. (1992). Production of vitamins, coenzymes and related biochemicals by biotechnological processes. J Chem Tecbnol Biotechnol 53, 313-327.

Vanni, P., Giachetti, E., Pinzauti, G. \& McFadden, B. A. (1990).

Comparative structure, function and regulation of isocitrate lyase, an important assimilatory enzyme. Comp Biochem Pbysiol 95B, 431-458.
Yoneda, F. (1984). Riboflavin $\left(\mathrm{B}_{2}\right)$. In Kirk-Otbmer Encyclopedia of Chemical Technology, pp. 108-124. Edited by M. Grayson \& D. Ekroth. New York: Wiley.

Received 12 May 1995; revised 11 September 1995; accepted 11 October 1995. 